\title{
Interaction of phagocytosed Bonamia sp. (Haplosporidia) with haemocytes of oysters Tiostrea chilensis
}

\author{
P. M. Hine, B. Wesney \\ Fisheries Research Centre, Ministry of Agriculture and Fisheries, PO Box 297, Wellington, New Zealand
}

\begin{abstract}
The interaction between the haplosporidian pathogen Bonamia sp. and the haemocytes of oysters Tiostrea chilensis was studied ultrastructurally and using ultracytochemistry for the lysosomal hydrolases, $\beta$-glycerophosphatase ( $\beta$-GPase), cytidine monophosphatase (CMPase), thiamine pyrophosphatase (TPPase), and $\beta$-galactosidase. Although fine and coarse granulocytes, serous (brown) cells and hyalinocytes were present, agranular precursors of fine granulocytes (progranulocytes), degranulated coarse granulocytes, hyalinocytes and serous cells commonly phagocytosed Bonamia sp. A sequence of infection from initial occupation of tight phagosomes to formation of an enlarged phagosome or parasitophorous vacuole (PV), which sometimes broke down, occurred in all infected haemocytes. Enlargement of the phagosome membrane to eventually form a PV coincided with formation of bilaminar vesicles in the lipoid bodies of parasites and their release from an indented area of the parasite surface. Too few infected granulocytes were observed to determine whether phagosome modification blocked lysosome-phagosome fusion. Vesicular CMPase and TPPase were produced by agranular haemocytes containing phagocytosed Bonamia sp. and passed into tight phagosomes. Despite some endocytosis of these enzymes by Bonamia sp., very few parasites appeared dense or moribund. From the orientation of lipoid bodies toward the phagosome lumen, and release of $\beta$-GPase into the lumen from the lipoid bodies, parasite hydrolytic enzymes in lipoid bodies may function in parasite nutrition, by extracellular digestion of host haemocyte cytoplasm.
\end{abstract}

KEY WORDS: Bonamia sp. Oyster haemocytes Phagosome:lysosome interactions - Enzymes · Parasitophorous vacuole

\section{INTRODUCTION}

Of all forms of parasitism, the obligate intracellular parasitism of phagocytic haemocytes presents some of the greatest barriers to survival. Pathogens of mammals that utilise professional phagocytes (granulocytes, macrophages) during their life cycles, have to survive oxygen-dependent $\left(\mathrm{H}_{2} \mathrm{O}_{2}, \mathrm{O}_{2}^{-}\right)$and oxygenindependent (lymphokines, $\gamma$-interferon, complement) killing mechanisms, phagosome acidification, and destruction by lysosomal acid hydrolases. Despite this, diverse mammalian pathogens, such as Mycobacteria (Mor et al. 1988), Toxoplasma gondii (McLeod et al. 1991), microsporidians (Weidner \& Sibley 1985), Leishmania spp. (Mauël 1990) and other trypanosomatids (McCabe \& Mullins 1990), successfully survive and replicate in phagocytes. Survival is achieved by blocking or evading phagocyte activation (McLeod et al. 1991), suppressing the respiratory burst (Sibley 1989, McCabe \& Mullins 1990, McLeod et al. 1991), preventing phagosome-lysosome fusion (Nichols \& O'Connor 1981, D'Arcy Hart et al. 1987, Sibley 1989, McLeod et al. 1991), and secreting substances that may form a protective barrier (Mauël 1990), modify the compartment occupied (de Carvalho \& de Souza 1989), or create a parasitophorous vacuole (PV) (Joiner et al. 1990).

Bonamia spp. are obligate haplosporidian parasites of oysters (e.g. Ostrea spp., Tiostrea chilensis) (Pichot et al. 1979, Dinamani et al. 1987) that are phagocytosed by, and replicate in, haemocytes. In Ostrea edulis, Bonamia ostreae is primarily phagocytosed by granulocytes (Balouet et al. 1983, Balouet \& Poder 1985. Chagot et al. 1992, Mourton et al. 1992), in which it appears to suppress the respiratory burst (Hervio et 
al. 1988, Jean-Chagot 1989, Hervio 1992). The dense lipoid bodies of $B$. ostreae contain cytidine monophosphatase (CMPase) and, as in Leishmania spp. (Mauël 1990), B. ostreae may use this acid phosphatase to protect itself from host haemocyte defence mechanisms (Hervio et al. 1991). The lipoid bodies of Bonamia sp in T. chilensis do not appear to contain CMPase, but may contain $\beta$-glycerophosphatase ( $\beta$-GPase), another acid phosphatase (Hine \& Wesney 1994, this issue).

This study was carried out to determine which haemocytes in Tiostrea chilensis phagocytose Bonamia sp., and how parasite lipoid bodies function after haemocyte phagocytosis. As lysosomal enzymes are used by phagocytes to degrade endocytosed material, the distributions of 4 lysosomal enzymes ( $\beta$-GPase, CMPase, thiamine pyrophosphatase, and $\beta$-galactosidase) were studied in haemocytes phagocytosing Bonamia sp.

\section{MATERIAL AND METHODS}

Infected oysters were opened, and the heart was removed and cut in two. Imprints were made with one half, and the other half was fixed for ultrastructural or enzyme cytochemical studies. Imprints were stained with Hemacolor ${ }^{\text {TM }}$ (Merck), microscopically examined, and heavily infected oysters selected for further study.

Fine structure. Hearts were fixed in $2.5 \%$ glutaraldehyde in $0.22 \mu \mathrm{m}$ filtered seawater (FSW) for 1 to $2 \mathrm{~h}$ washed twice in FSW, post-fixed in $1 \% \mathrm{OSO}_{4}$ for $1 \mathrm{~h}$ stained en bloc with $5 \%$ uranyl acetate in $0.1 \mathrm{M}$ sodium acetate buffer for $45 \mathrm{~min}$, dehydrated in ascending 150 to $100 \%$ ) ethyl alcohol, embedded in Araldite, sectioned, stained with $5 \%$ uranyl acetate for $10 \mathrm{~min}$ and $5 \%$ lead citrate for 5 to 6 min, and examined on a Philips 420ST transmission electron microscope (TEM).

Enzyme cytochemistry. The following ultracytochemical techniques were used: $\beta$-glycerophosphatase $(\beta$ GPase) (Robinson \& Karnovsky 1983), cytidine monophosphatase (CMPase) (Hervio et al. 1991), thiamine pyrophosphatase (TPPase) (Robinson \& Karnovsky 1983), and $\beta$-galactosidase (Rhodes \& Blom 1986). Details of these techniques, and modifications to them, are given in Hine \& Wesney (1994).

\section{RESULTS}

\section{Haemocytes}

Four haemocyte types were distinguished. (1) Fine granulocytes had a central or slightly eccentric round nucleus, with a uniform margin of heterochromatin, and circular to ovoid granules. Two forms were apparent; small cells $(\mathrm{Sg})$ with a high nucleus to cytoplasm ratio, and large circular to ovoid granules (Fig. 1) that stained moderately to strongly for $\beta$-GPase and CMPase, and larger cells $(\mathrm{Lg})$ with a lower nucleus to cytoplasm ratio that sometimes contained lipid bodies reactive for $\beta$-galactosidase, and had granules with a dark core or lacking a core (Fig. 2), that reacted weakly for CMPase, but were moderate or strong for $\beta$-GPase. Both types were frequently observed degranulating.

(2) Coarse granulocytes ( $\mathrm{Cg}$ ) had an eccentric nucleus, short profiles of rough endoplasmic reticulum (rER) and large irregular granules (Fig. 3) that showed patchy moderate, or rarely strong, reaction for $\beta$-GPase, CMPase and $\beta$-galactosidase. Cells lacking granules, but otherwise indistinguishable from $\mathrm{Cg}$, were frequently observed. A few that appeared to lack phagosomes contained particulate CMPase and TPPase in cytoplasmic vesicles, and moderate (CMPase) to strong (TPPase) particulate reaction product was observed in cells with phagosomes containing necrotic debris.

(3) Large cells with an eccentric irregular nucleus bordered by a thin band of heterochromatin, and containing large irregular flecked masses (Fig. 4) were identified as serous or brown cells.

(4) Hyalinocytes were often irregular in shape, had an eccentric nucleus with mitochondria grouped nearby (Fig. 5), and contained a few cytoplasmic, sometimes dense, vesicles. Rarely, weak $\beta$-GPase was seen in vesicles.

\section{Fine structure of host-parasite interaction}

Bonamia sp. most often infected agranular cells resembling degranulated $\mathrm{Cg}$ (Fig. 6), agranular cells with lipid bodies and an ovoid nucleus with uniformly

Figs. 1 to 6. Bonamia sp. infecting Tiostrea chilensis. Haemocytes present. Fig. 1. Small cell showing central nucleus, uniform marginated heterochromatin, and spherical to ovoid granules. $\times 14540$. Fig. 2 . Larger cell showing the ovoid to round nucleus with uniform marginated heterochromatin, and granules with a dense or missing core CMPase unstained, $\times 10090$. Fig. 3. Coarse granulocytes, $\mathrm{Cg}$, showing the eccentric irregular nucleus with prominent nucleolus and cytoplasm rich in ribonucleoside endoplasmic reticulum, rER. Note lack of clustering of granules around Bonamia sp. inside a developing parasitophorous vacuole, PV (arrow). $\beta$-GPase, $\times 9880$. Fig. 4. Serous cell showing the nucleus (N), characteristic large irregular flecked inclusions ( $*$ ), and phagocytosed Bonamia sp. (B) in a developing PV (arrow). $\beta$-GPase control, $\times 11500$. Fig. 5 . Hyalinocyte with characteristic perinuclear grouping of mitochondria. The Bonamia sp. is in a large phagosome and has a $\beta$-GPase-positive lipoid body. $\beta$-GPase, $\times 11280$. Fig. 6. Agranular haemocyte with a nucleus similar to $\mathrm{Cg}$ (Fig. 3), a central Golgi complex, some rER, and containing 3 Bonamia sp. (B). TPPase unstained, $\times 12330$ 

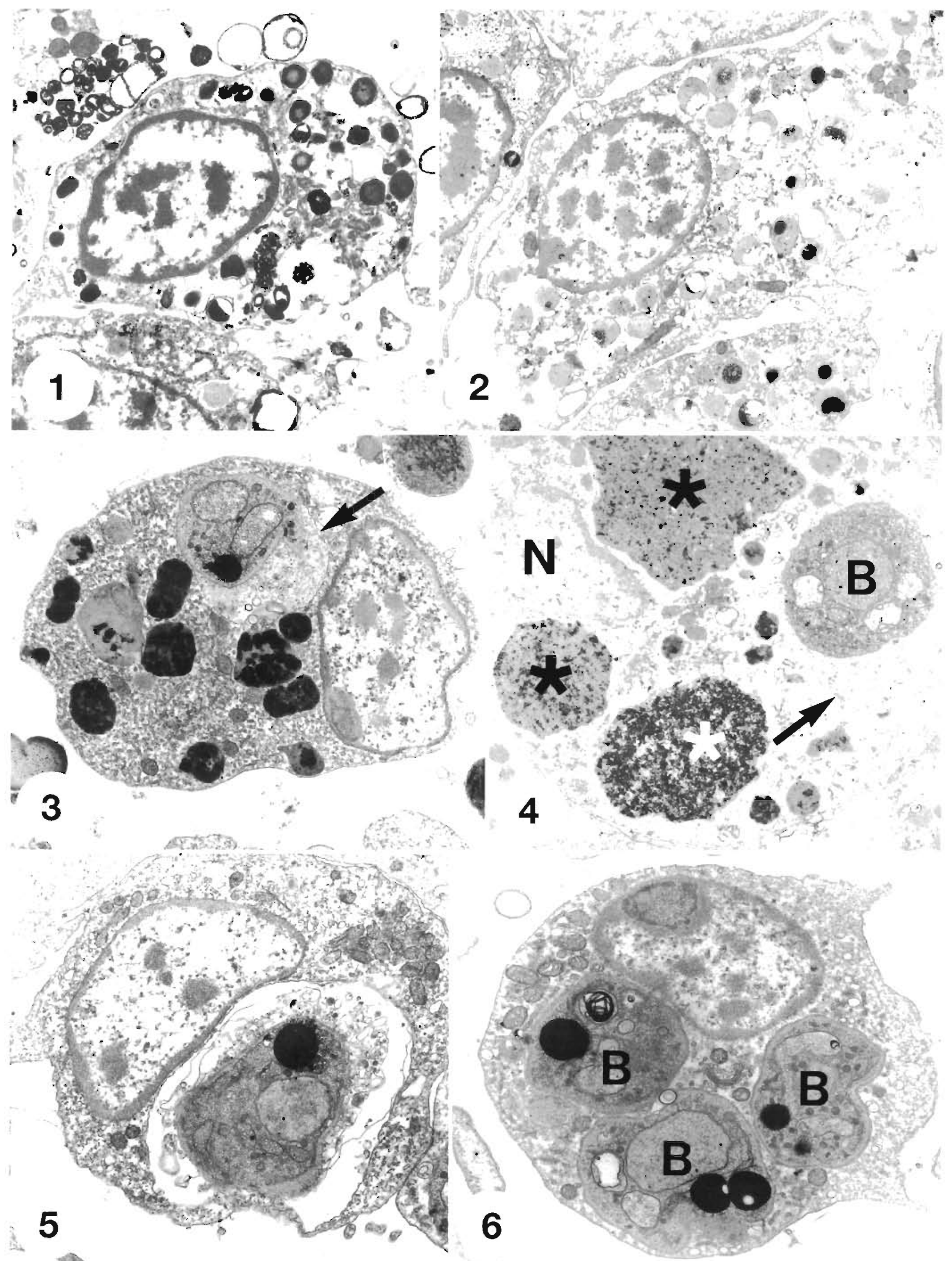

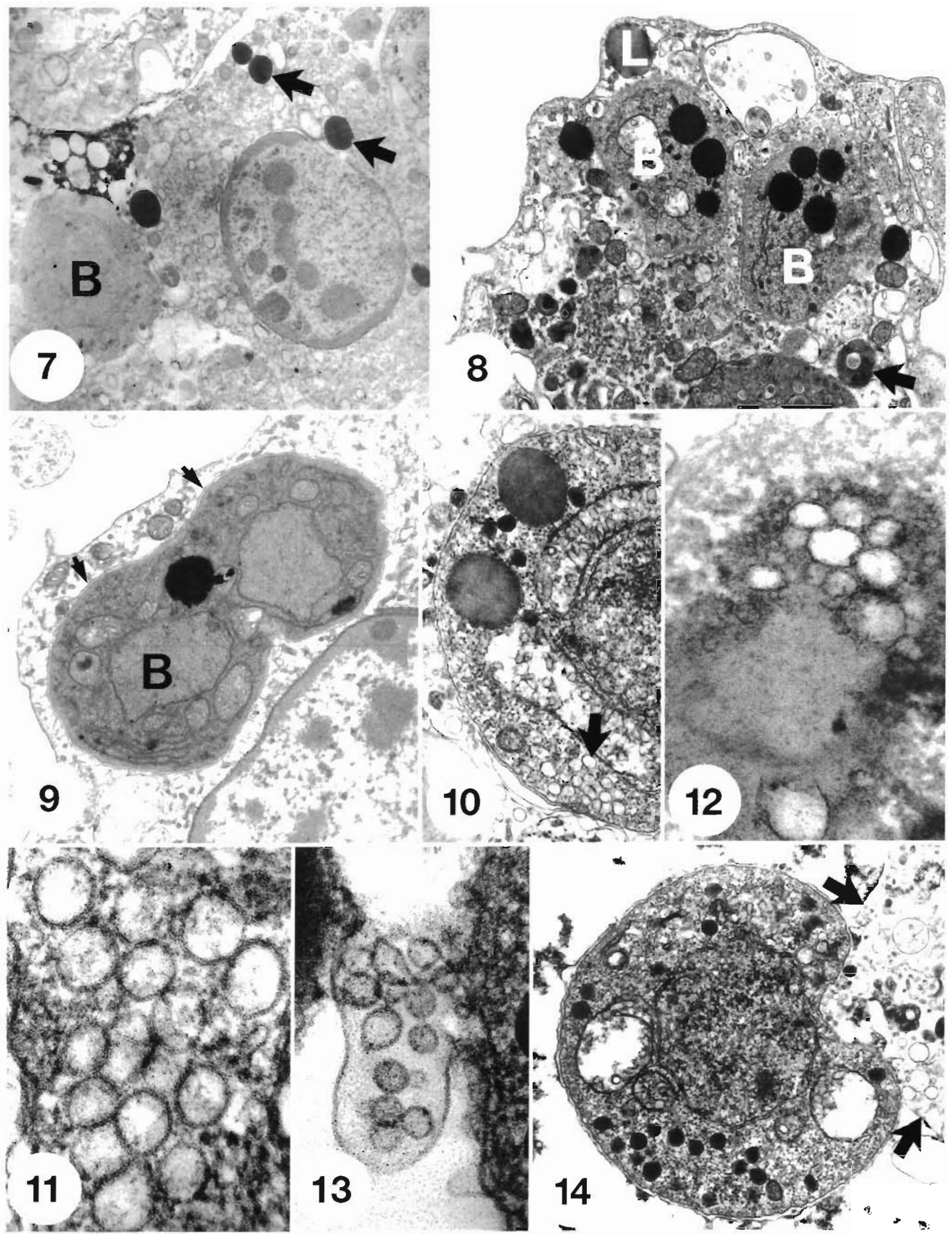
Figs. 7 to 14 . Bonamia sp.: haemocyte interaction in Tiostrea chilensis. Fig. 7 . Agranular haemocyte showing the ovoid nucleus with uniform heterochromatin around most of the margin, ovoid $\beta$-galactosidase positive lipid inclusions (arrows), many $r E R$ profiles, and a Bonamia sp. (B) attached to the surface. $\beta$-Galactosidase unstained, $\times 9610$. Fig. 8 . Granulocyte showing ovoid to round granules, some with light cores (arrow), a lipid inclusion (L), and 2 Bonamia sp. (B). B-GPase, $\times 13$ 390. Fig. 9 . Bonamia sp. (B) dividing in a tight phagosome within an agranular haemocyte rich in rER. Note the uniformity of the space between the phagosome membrane (arrows) and the parasite $\times 15900$. Fig. 10. Presence of bilaminar secretory vesicles within a Bonamia sp. (arrow) $\times 28900$. Fig. 11. Detail of the vesicles in Fig. $9 . \times 134000$. Fig. 12. Similar vesicles to those in Figs. 9 \& 10 within a parasite lipoid body. TPPase+L-tartrate as inhibitor, $\times 105000$. Fig. 13. Bilaminar secretory vesicles passing out of Bonamia sp., on the right. $\times 90130$. Fig. 14. Typical indentation of the parasite from which secretory vesicles are being shed, and which are confined within the phagosome membrane (arrows) $\times 22890$

marginated sparse heterochromatin (Fig. 7), hyalinocytes (Fig. 5), serous cells (Fig. 4) and Cg (Fig. 3), and very rarely $k 1 \%$ of infections) fine granulocytes (Fig. 8). A sequence of infection appeared to occur from initial binding of the parasite to the phagocyte surface (Fig. 7) to presence of Bonamia sp. in unmodified tight phagosomes (Fig. 9), and subsequently formation of PVs containing parasites. In unmodified, tight phagosomes there was a gap of $25 \mathrm{~nm}$ between the parasite and host membranes (Fig. 9). This space enlarged when ovoid bilaminar vesicular particles, $110 \times 90 \mathrm{~nm}$ with $5 \mathrm{~nm}$ between the membranes, formed inside the parasite (Figs. 10 \& 11) apparently within the lipoid bodies (Fig. 12), and were released from its surface (Fig. 13). In $>90 \%$ of Bonamia sp., at all developmental stages, particles were released from an indented or concave region of the parasite surface (Figs. 14 \& 15). Particle release appeared to coincide with host phagosome membrane enlargement, forming a PV around the parasite (Fig. 16).

When 2 or more parasites occurred together, the PV around each was joined to form a common vacuole with the parasites around its periphery (Fig. 16). The host membrane could be seen between and around the parasites, which often had their lipoid bodies orientated toward the lumen of the PV (Fig. 17). The lipoid bodies were often at the parasite surface and either appeared to protrude from it (Fig. 18), or were occasionally seen outside the parasite (Fig. 17). In the few granule-containing haemocytes with phagocytosed Bonamia sp., haemocyte granules did not fuse with the phagosome membrane (Fig. 3). Sometimes the PV membrane appeared to break and much of the haemocyte cytoplasm was replaced by parasites amid disintegrating host granules and parasite lipoid bodies, haemocyte organelles, and disorganized membranes.

\section{Enzyme cytochemistry}

Parasites were rarely seen within granular cells, and uninfected cells lacking membrane-bound granules showed little cytoplasmic enzyme activity. However, lipid bodies in agranular cells were positive for $\beta$ galactosidase (Fig. 7). When haemocyte granules lay near a disintegrating $P V$, their $\beta$-GPase did not surround the parasites (Fig. 8). Lipoid bodies in Bonamia $\mathrm{sp}$. were weakly to moderately positive for $\beta$-GPase, and when lipoid bodies protruded from the parasite surface some $\beta$-GPase was released into the PV (Fig. 15). Extracellular $\beta$-GPase was not observed to coat the parasite surface.

In tight phagosomes of agranular cells CMPase coated the parasite surface and appeared to derive from haemocyte vesicles fusing with the unmodified phagosomes (Fig. 19). Haemocyte vesicles did not have distinct membranes and reaction product often appeared particulate (Fig. 20). Similar deposits were occasionally seen, apparently endocytosed, within the parasites (Fig. 21). CMPase was also observed in tight phagosomes of serous cells (Fig. 22). Parasites in the PV were not coated with CMPase.

TPPase showed similar distribution to CMPase, being present in tight phagosomes and as loose particulate reaction product in disorganized masses where the phagosome was more voluminous (Fig. 23). TPPase occurred in laminated structures within vesicles (Fig. 24), and similar configurations occurred near the parasite surface (Fig. 23). Similar reaction product was observed as intracytoplasmic deposits (Fig. 23), which only occurred in parasites surrounded by reaction product, and may therefore have been endocytosed. Many parasites showed partial loss of lipoid body content (Figs. 6, 15 \& 20) which may have included weak TPPase activity (Figs. 12 \& 25), and occasionally lipoid body contents appeared to pass into the phagosome (Fig. 25). Most parasites appeared unaffected by TPPase, and Bonamia sp. was frequently observed leaving haemocytes (Fig. 26). No reaction product was observed in sections incubated without substrate.

The lipid bodies of some agranular haemocytes contained $\beta$-galactosidase (Figs. $7 \& 27$ ). These lipid bodies were not membrane bound, and although they appeared to coalesce, they did not fuse with the phagosome membrane (Fig. 27). 


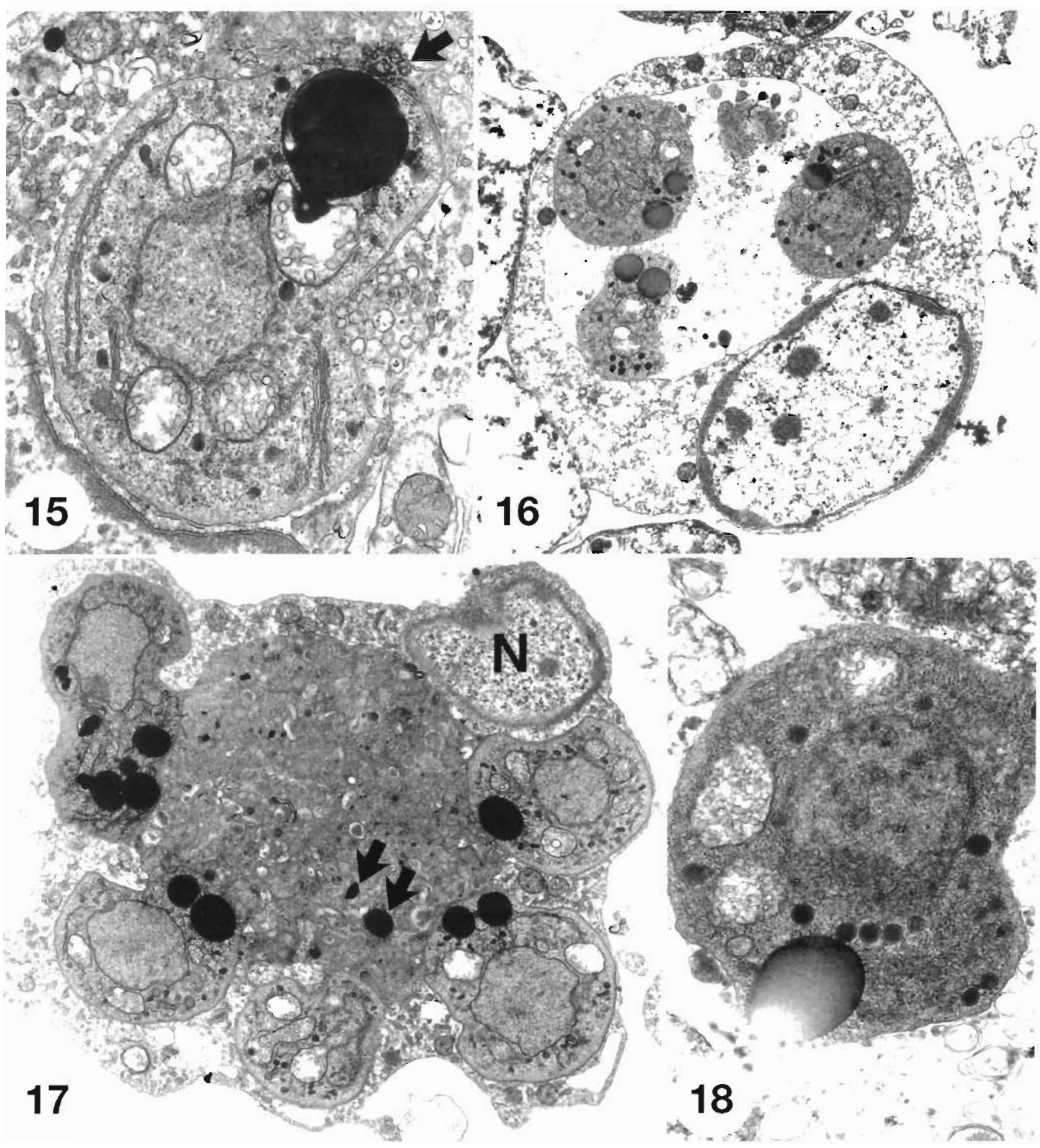

Figs 15 to 18 Bonamiasp haemocyte interaction un Tiostrea chyensis Fig 15. Agranular haemocyte rich in rER with a phagocytosed Bonamia sp Note the site of parasite surtace indentation and vesicle shedding in relation to a dense body reacted for $\beta$-GPase Some enzyme is on the surface of the parasite (arrow) $\beta$-GPase, $\times 23330$ Fig. 16. Agranular haemocyte rich in rER contaning 3 Bonama sp in a well-formed PV $\times 8210$ Flg. 17. Agranular haemocyte showing the cell nucleus (N), and 5 Bonamia sp joined by a common intact phagosome membrane Note the Bonamia sp lipold bodies are orientated toward, and 2 are in (arrows), the PV lumen. $\beta$-GPase, $\times 8370$ Fig. 18 . Lipoid body protruding from and breaking the parasite surface, with loss of content on lumenal side $\times 27620$ 


\section{DISCUSSION}

The $\mathrm{Lg}$ of Tiostrea chilensis are similar to those reported as granulocytes from Ostrea edulis by Auffret (1989) and Jean-Chagot (1989). The Sg resemble the hyalinocyte of $O$. edulis in Auffret (1989), and the small hyalinocyte of Jean-Chagot (1989). However, the 'electron-dense vesicles' described by Auffret (1989) are granules, and in nucleus:cytoplasm ratio, nuclear position and shape, and $\beta$-GPase staining in this study, the $\mathrm{Sg}$ resembles the granulocyte of Crassostrea gigas illustrated in Fig. 2e in Auffret (1989). Also, the hyalinocyte described here resembles the hyalinocyte of $C$. gigas, not the hyalinocyte of $O$. edulis, reported by Auffret (1989). The $\mathrm{Cg}$ of $\mathrm{T}$. chilensis may be a more developed form of the small granulocyte; however, as this cell was frequently observed and was never seen with the uniform granules of small granulocytes, it is considered a separate cell type. With the exception of $\mathrm{Sg}$, which sometimes reacted strongly for CMPase, observations made here support Jean-Chagot's (1989) suggestion that $\beta$-GPase is stronger in granulocytes than CMPase.

Most haemocytes phagocytosing Bonamia sp. were agranular, rich in short profiles of rER, with or without lipid bodies; their ontogeny is uncertain. On the basis of perinuclear grouping of mitochondria, some appeared to be hyalinocytes. The lipid bodies of others contained $\beta$-galactosidase, as do lipid bodies sometimes seen in developing $\mathrm{Lg}$ (Hine unpubl. data), and on the basis of nuclear morphology these cells may be granulocyte precursors (progranulocytes). It is unlikely that they are degranulated Lg as typical Lg granules were never observed in them. Also, despite the presence of many Lg in oysters co-infected with Bonamia sp. and bacterial infections, Lg very rarely $(<1 \%)$ phagocytosed Bonamia sp. Other agranular cells may be degranulated $\mathrm{Cg}$. Those with particulate CMPase and TPPase resemble haemocytes in Crassostrea virginica which are phagocytic in systemic Haplosporidium nelsoni (MSX) infections (Fig. 19 in Scro \& Ford 1990). In vitro studies on $C$. virginica haemocyte interaction with MSX plasmodia have shown that granulocytes and agranular cells only phagocytosed damaged or killed plasmodia, and that granulocytes retreated rapidly after contact with plasmodia (Ford et al. 1993a). The haemocytes of $C$. virginica probably function more in wound repair than MSX phagocytosis (Ford et al. 1993b). Tiostrea chilensis agranular haemocytes containing necrotic debris or phagocytosed Bonamia sp. had more particulate CMPase and TPPase reaction product than those that were non-phagocytic, and may also function in wound repair.

The haemocytic response of Tiostrea chilensis to Bonamia sp. differs markedly from the response of oysters to $B$. ostreae. In Crassostrea gigas and Ostrea edulis, B. ostreae infects every haemocyte type (Chagot et al. 1992), but, even allowing for change in composition and increase in granulocytes over time (Mourton et al. 1992), the primary phagocytes of B. ostreae are fine granulocytes (Balouet et al. 1983, Balouet \& Poder 1985, Chagot et al. 1992, Mourton et al. 1992). Similarly in winter mortality of rock oysters (Crassostrea commercialis), caused by another haplosporidian, Mikrocytos roughleyi, only granulocytes are involved (Balouet et al. 1983). The apparent difference of haemocyte type involved may be partly due to nomenclature, as some cells phagocytosing $B$. ostreae resemble cells here called progranulocytes (Fig. 1 in Balouet et al. 1983). However, haemocytes regarded as granulocytes in both $T$. chilensis and in $O$. edulis (Fig. 3A in Mourton et al. 1992), were very rarely observed to phagocytose Bonamia sp. in this study. As Bonamia sp. also infects $O$. angasi in Australia, and the $O$. angasi haemocyte response is granulocytic (Hine unpubl. obs.), a comparative study of this pathogen in both oyster species may clarify oyster haemocyte function.

Phagocytosis of Bonamia sp. was not observed herein, but probably resembled phagocytosis of $B$. ostreae by Ostrea edulis haemocytes which actively endocytose Bonamia sp., rather than the parasite invading the haemocytes (Chagot et al. 1992). Lack of observation of phagocytosis may be due to the speed (<30 min) with which infection occurs (Mourton et al. 1992). Parasites were seen in tight phagosomes, but with the release of bilaminar particles the phagosome membrane enlarged to form a space between the parasite and host. Other obligate parasites of phagocytes release similar particles (Sibley 1989, McLeod et al. 1991, Pimenta et al. 1991) that vary in appearance with parasite species and strain (Sibley 1989). Purified bilaminar vesicles from Toxoplasma gondii (Fig. 8 in Sibley et al. 1986) which resemble those observed herein, may derive from rhoptries (Nichols et al. 1983), dense granules (Leriche \& Dubremetz 1990) or the parasite surface (Sibley \& Krahenbuhl 1988). They are inserted into the host phagosome membrane to form the PV (Joiner et al. 1990), and may prevent phagosome-lysosome fusion (Nichols et al. 1983, Joiner et al. 1990) or may be used to process and transport host metabolites necessary for parasite nutrition (Sibley 1989).

The similarity in production of bilaminar vesicles coinciding with enlargement of the host membrane to form a PV in Bonamia sp. and Toxoplasma gondii suggests a similar mechanism of $\mathrm{PV}$ formation. $B$. ostreae also occupies PVs containing vesicular and membraneous inclusions (Fig. 69 in Jean-Chagot 1989), and it is often kidney-shaped, with a concave surface, in haemocytes (Montes et al. 1994). However, 


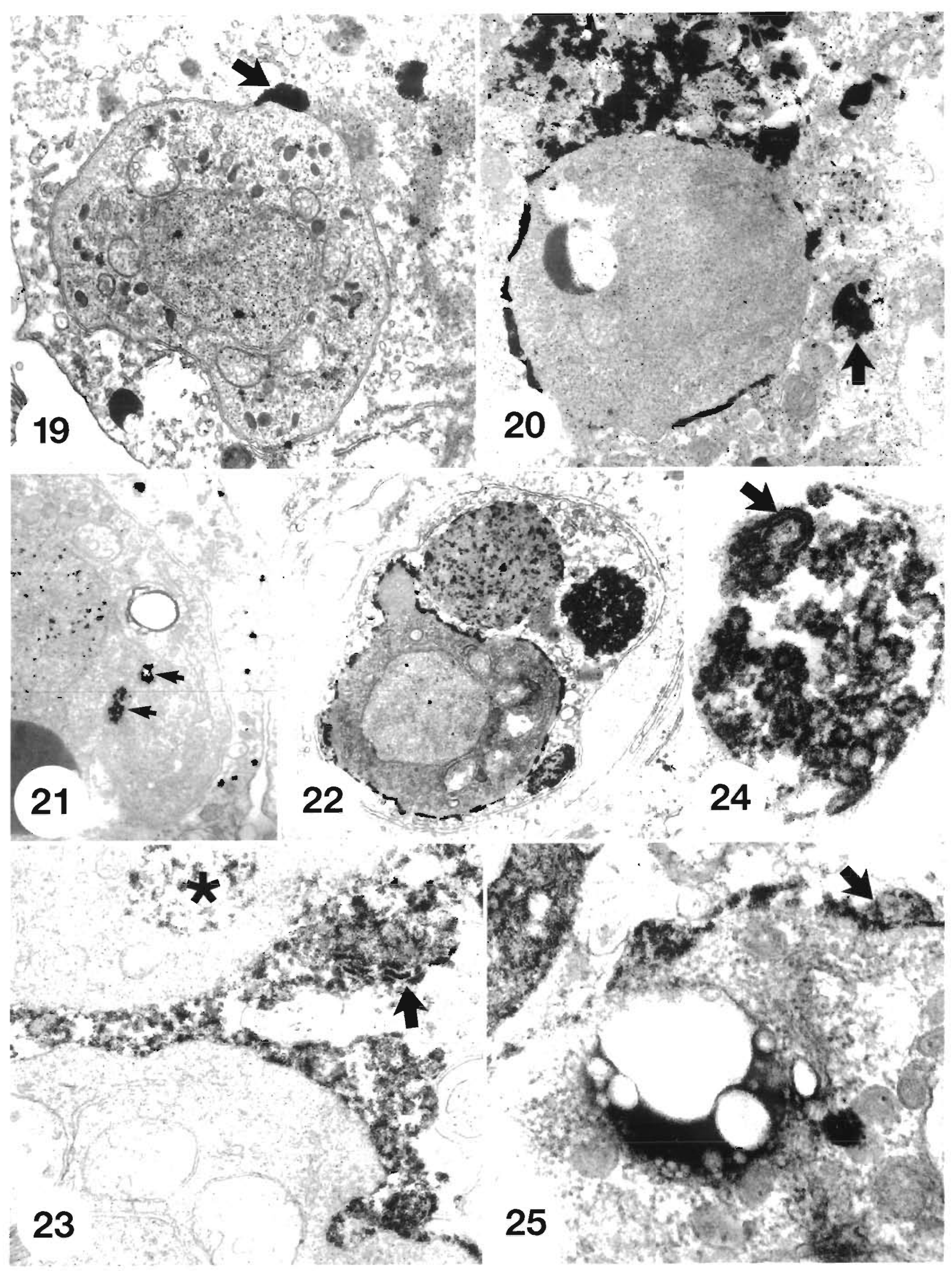


Figs 19 to 25. Bonamia sp. and haemocyte cytochemistry in Tlostrea chilensis. Fig. 19. CMPase-positive vesicles in the cytoplasm, and along a tight phagosome (arrow), in a rER rich agranular haemocyte. CMPase, $\times 19800$. Fig. 20. Particulate (arrow) and vesicular CMPase reaction around a phagocytosed Bonamia sp. in a rER rich agranular haemocyte. Note loss of parasite lipoid body content. CMPase unstained, $\times 23$ 170. Fig. 21. Bonamia sp. in a rER rich granulocyte showing CMPase positive material (arrows) that has probably been endocytosed. CMPase unstained, $\times 28460$. Fig. 22. Bonamia sp. in a serous cell showing CMPase within the tight phagosome around the parasite. CMPase, $\times 14840$. Fig. 23. Particulate TPPase around 2 Bonamia sp. showing the laminar reaction product (arrow) and endocytosed $(*)$ reaction product. TPPase unstained $\times 42880$. Fig. 24. Laminar TPPase reaction product (arrow) in cytoplasmic vesicular aggregate. TPPase unstained, $\times 52380$. Fig. 25 . Lupoid body showing loss of TPPase positive content near the parasite surface, and reaction product around the parasite (arrow). TPPase, $\times 52000$

T. gondii forms large PVs if it actively invades the cell, but only lies in small vacuoles if antibody coated and passively endocytosed using the Fc receptor (Silva et al. 1982, de Carvelho \& de Souza 1989, McLeod et al. 1991). Bonamia sp. is passively taken up (Chagot et al. 1992) and may form a large PV

In Toxoplasma gondii the formation of a PV after active invasion results in inhibition of phagosome-lysosome fusion (McLeod et al. 1991), and the lack of lysosome-phagosome seen herein (Figs. 3 \& 8) suggests fusion may be similarly inhibited. When $T$. gondii is passively endocytosed into small vacuoles, phagosome-lysosome fusion is not inhibited (Joiner et al. 1990. McLeod et al. 1991). In our study, CMPase and TPPase were observed coating parasites in tight phagosomes. Although it was unclear whether this enzyme derived from parasite lipoid bodies, or from haemocytes, fusion of CMPase-containing granules with phagosomes apparently occurred (Figs. 19 \& 20). Like Toxoplasma gondii, Bonamia sp. is endocytosed by different mechanisms that affect the ability of haemocyte lysosomes to fuse with phagosomes. However, observations on B. ostreae (Jean-Chagot 1989 , Chagot et al. 1992) do not suggest different endocytotic mechanisms. Alternatively, lysosome fusion may occur with unmodified tight phagosomes, before bilaminar vesicle modification of the phagosome membrane, but secretion of bilaminar vesicles modifies the phagosome to prevent lysosome fusion. Haemocyte lipid bodies do not fuse with phagosomes (Fig. 27) because of the lack of a bounding unit membrane.

The orientation of lipoid bodies toward the PV lumen (Fig. 17), and their protrusion (Fig. 18), exocytosis (Fig. 17) and loss of content (Figs. 6, 15, 20 \& 25) suggests they are functional at this stage of infection. They may perform 1 or more of 3 functions. Firstly they may release acid phosphatase to coat the parasite surface (see Hervio et al. 1991), as in Leishmania spp., to block host superoxide anion production (Mauël 1990). However, this role is now attributed to lipophosphoglycan (LPG), which may be formed from acid phosphatase by addition of a carbohydrate structure in the Golgi com-

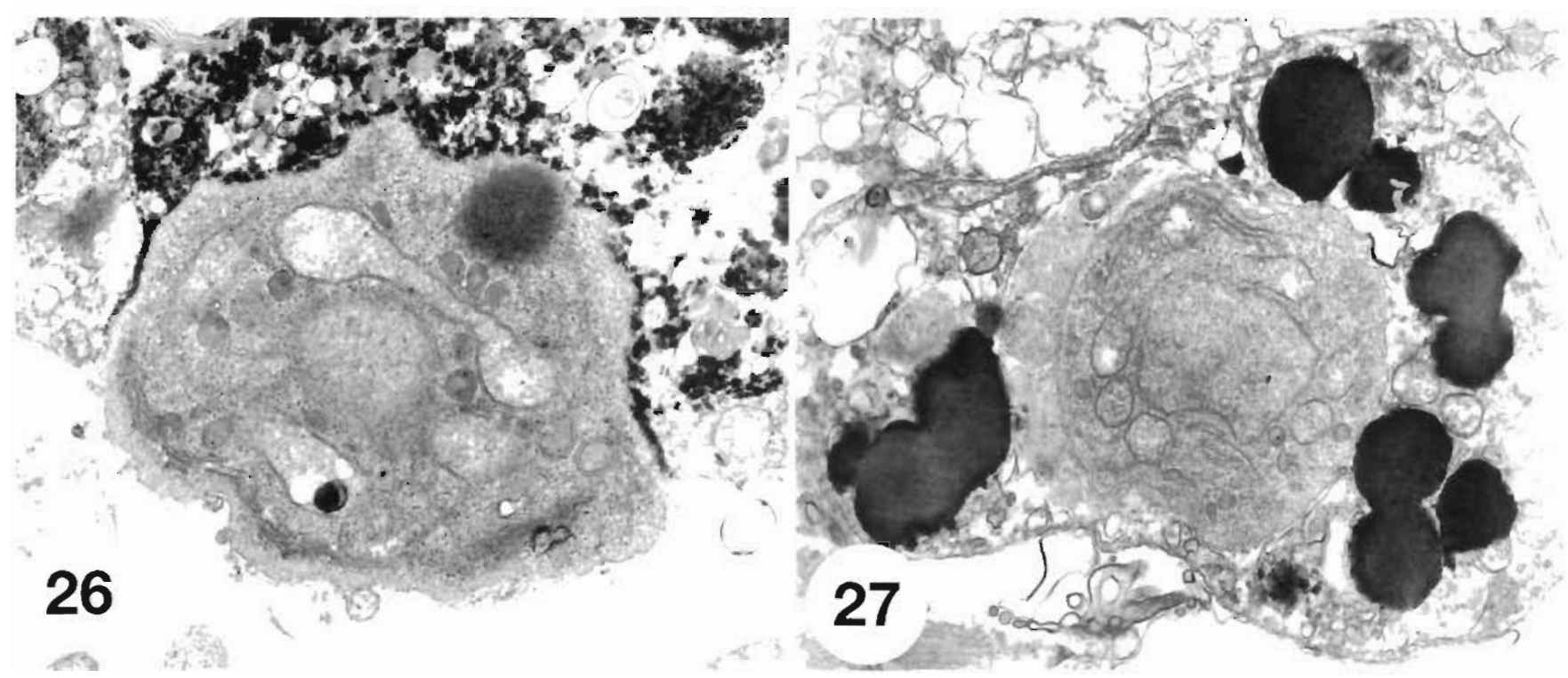

Figs. 26 \& 27. Bonamia sp. infecting Tiostrea chilensis. Fig. 26. Bonamia sp. egressing from a degenerating haemocyte. TPPase, $\times 25120$. Fig. 27 . Lipid bodies in a haemocyte around a parasite in a developing PV. $\beta$-Galactosidase, $\times 16010$ 
partment (Bates et al. 1990). LPG attenuates (McNeely \& Turco 1990) or depresses (El-On et al. 1990) the host respiratory burst, by inhibiting protein kinase $C_{\text {, a }}$ modulator of macrophage oxidative metabolism (Mauël 1990). There was no evidence of $\beta$-GPase or CMPase being used to coat the parasite surface.

Secondly, Bonamia sp. Iipoid bodies are rich in unsaturated lipids (Hine \& Wesney 1994) and may be involved in membrane traffic. Bilaminar membraneous vesicles are shed from near the lipoid bodies. Bonamia sp. endocytoses membranes and appears to synthesise lipids through the Golgi and endoplasmic reticulum compartments to form lipoid bodies (Hine \& Wesney 1994).

Thirdly, lipoid bodies contain $\beta$-GPase, and possibly TPPase, which appeared to pass from lipoid bodies into the surrounding medium (Fig. 15), and lipoid bodies were orientated toward the area of disorganized haemocyte cytoplasm (Fig. 17). Therefore, as Bonamia sp. grows and divides (Fig. 9) inside haemocytes, a possible role for the lysosomal enzymes is in nutrition, as suggested for Leishmania mexicana lipoid bodies by Hassan \& Coombs (1987).

In conclusion, Bonamia sp. is mainly phagocytosed by agranular haemocytes that lack a lysosomal system capable of injuring or destroying the parasite. Lysosomephagosome fusion was not observed in infected granulocytes. Lack of fusion may be due to membraneous vesicles excreted by the parasite modifying tight phagosomes to form a PV and prevent lysosome fusion. Membraneous vesicles appear to derive from lipoid bodies, which may also function in parasite nutrition.

Acknowledgements. This work would not have been possible without the expertise that Karen Reader and Rob Thompson of the Electron Microscope Unit, Victoria University of Wellington, have brought to this study. We are also grateful to Dr Dominique Hervio and Dr Evelyne Bachère of IFREMER for making available unpublished theses and papers

\section{LITERATURE CITED}

Auffret, M. (1989). Comparative study of the hemocytes of two oyster species: the European flat oyster, Ostrea edulis, Linnaeus 1750 and the Pacific oyster, Crassostrea gigas (Thunberg, 1793). J. Shellfish Res. 8: 367-373

Balouet, G., Poder, M. (1985). A consideration of the cellular reactions in bivalve molluscs, with emphasis on haemocytic diseases. In: Ellis, A. E. (ed.) Fish and shellfish pathology. Academic Press, London, p 381-385

Balouet, G., Poder, M., Cahour, A. (1983). Haemocytic parasitosis: morphology and pathology of lesions in the French flat oyster, Ostrea edulis L. Aquaculture 34: 1-14

Bates, P. A., Hermes, I., Dwyer, D. M. (1990). Golgi-mediated post-translational processing of secretory acid phosphatase by Leishmania donovani promastigotes Molec. Biochem. Parasitol. 39: 247-256

Chagot, D., Boulo, V., Hervio, D., Mialhe, E., Mourton, C. Grizel, H. (1992). Interactions between Bonamia ostreae
(Protozoa: Ascetospora) and hemocytes of Ostrea edulis and Crassostrea gigas (Mollusca: Bivalvia): entry mechanisms. J. Invertebr. Pathol. 59: 241-249

D'Arcy Hart, P., Young, M. R., Gordon, A. H., Sullivan, K. H. (1987). Inhibition of phagosome-lysosome fusion in macrophages by certain Mycobacteria can be explained by inhibition of lysosomal movements observed after phagocytosis. J. exp. Med. 166: 933-946

de Carvalho, L., de Souza, W. (1989). Cytochemical localization of plasma membrane enzyme markers during interiorization of tachyzoites of Toxoplasma gondii by macrophages. J. Protozool. 36: 164-170

Dinamani, P., Hine, P. M., Jones, J. B. (1987). Occurrence and characteristics of the haemocyte parasite Bonamia sp. in the New Zealand dredge oyster Tiostrea lutaria. Dis. aquat. Org. $3: 37-44$

El-On, J., Zvillich, M., Sarov, I. (1990). Leishmania major inhibition of the chemiluminescent response of human polymorphonuclear leukocytes by promastigotes and their excreted factors. Parasit. Immunol 12: 285-295

Ford, S. E., Ashton-Alcox, K. A., Kanaley, S. A. (1993a). In vitro interactions between bivalve hemocytes and the oyster pathogen Haplosporidium nelsoni (MSX). J. Parasitol. 79: $255-265$

Ford, S. E., Kanaley, S. A., Littlewood, D. T. J. (1993b). Cellular responses of oysters infected with Haplosporidium nelsoni: changes in circulating and tissue-infiltrating hemocytes. J. Invertebr. Pathol. 61:49-57

Hassan, H. F., Coombs, G. H. (1987). Phosphomonoesterases of Leishmania mexicana mexicana and other flagellates. Molec. Biochem. Parasitol. 23: 285-296

Hervio, D. (1992). Contribution à l'étude de Bonamia ostreae (Ascetospora), protozoaire parasite de l'huitre Ostrea edulis (Bivalvia), et à l'analyse des interactions hôteparasite. Thèse, Université Blaise Pascal, ClermontFerrand

Hervio, D., Bachère, E., Mialhe, E., Grizel, H. (1988). Chemiluminescent responses of Ostrea edulis and Crassostrea gigas hemocytes to Bonamia ostreae (Ascetospora). Dev. comp. Immunol. 13: 449

Hervio, D., Chagot, D., Godin, P., Grizel, H., Mialhe, E. (1991). Localization and characterization of acid phosphatase activity in Bonamia ostreae (Ascetospora), an intrahemocytic protozoan parasite of the flat oyster Ostrea edulis (Bivalvia). Dis aquat. Org. 12: $67-70$

Hine, P. M., Wesney, B. (1994). The functional cytology of Bonamia sp. (Haplosporidia) infecting oysters Tiostrea chilensis: an ultracytochemical study. Dis. aquat. Org. 20: 207-217

Jean-Chagot, D. (1989). Caractérisation morphologique et tonctionnelle des hémocytes d'Ostrea edulis et de Crassostrea gigas, Mollusques Bivalves. Étude in vitro de leurs interactions avec le protozoaire Bonamia ostreae (Ascetospora). Thèse, École Pratique des Hautes Études, Université de Montpellier

Joiner, K. A., Fuhrman, S. A., Meittinen, H. M., Kasper, L. H., Mellman, I. (1990). Toxoplasma gondii: fusion competence of parasitophorous vacuoles in FC receptor-transfected fibroblasts. Science 249: 641-646

Leriche, M. A., Dubremetz, J. F. (1990). Exocytosis of Toxoplasma gondii dense granules into the parasitophorous vacuole after host cell invasion. Parasitol. Res. 76: 559-562

Mauel, J. (1990). Macrophage-parasite interactions in Leishmania infections. J. Leukocyte Biol. 47: 187-193

McCabe, R., Mullins, B. T (1990). Failure of Trypanosoma cruzi to trigger the respiratory burst of activated macrophages. Mechanism for immune evasion and impor- 
tance of oxygen-independent killing. J. lmmunol. 144: $2384-2388$

McLeod, R, Mack, D., Brown, C. (1991). Toxoplasma gondii new advances in cellular and molecular biology. Exp. Parasitol. 72: 109-121

McNeely, T B., Turco, S. J. (1990). Requirement of lipophosphoglycan for intracellular survival of Leishmania donovani within human monocytes. J. Immunol. 144: 2745-2750

Montes, J., Anadón, R., Azevedo, C. (1994). A possible life cycle for Bonamia ostreae on the basis of electron microscopy studies. J. Invertebr. Pathol. 63: 1-6

Mor, N., Goren, M. B., Pabst, M. J. (1988). Mycobacterium lepraemurium activates macrophages but fails to trigger release of superoxide anion. J. Immunol. 140: 3956-3961

Mourton, C., Boulo, V., Chagot, D., Hervio, D., Mialhe, E., Grizel, G. (1992). Interactions between Bonamia ostreae (Protozoa: Ascetospora) and hemocytes of Ostrea edulis and Crassostrea gigas (Mollusca: Bivalvia): in vitro system establishment. J. Invertebr. Pathol. 59: 235-240

Nichols, B. A., Chiappino, M. L., O'Connor, G. R. (1983). Secretion from the rhoptries of Toxoplasma gondii during host-cell invasion. J. Ultrastruct. Res. 83: 85-98

Nichols, B. A., O'Connor, R. (1981). Penetration of mouse peritoneal macrophages by the protozoon Toxoplasma gondii. New evidence for active invasion and phagocytosis. Lab. Invest. 44: 324-335

Pichot, Y., Comps, M., Tigé, G., Grizel, H., Rabouin, M.-A. (1979). Recherches sur Bonamia ostreae gen. n., sp. n., parasite nouveau de l'huitre plate Ostrea edulis L. Rev. Trav. Inst. Pèch. marit. 43: 131-140

Pimenta, P. F. P., Saraiva, E. M. B., Sacks, D. L. (1991). The comparative fine structure and glycoconjugate expression

Responsible Subject Editor: A. K. Sparks, Seattle, Washington, USA of three life stages of Leishmania major. Exp. Parasitol. 72 : 191-204

Rhodes, J.M. Blom, J. (1986). Cytochemical localization of $\beta$-galactosidase in resident and inflammatory peritoneal macrophages from C57BL mice. Histochemistry 86: $159-164$

Robinson, J. M., Karnovsky, M. J (1983). Ultrastructural localization of several phosphatases with cerium. J. Histochem. Cytochem. 31: 1197-1208

Scro, R. A., Ford, S. E. (1990). An electron microscope study of disease progression in the oyster, Crassostrea virginica, infected with the protozoan parasite, Haplosporidium nelsoni (MSX). In: Perkins, F. O., Cheng, T C. (eds.) Pathology in marine science. Academic Press, New York, p. $229-254$

Sibley, L. D. (1989). Active modification of host cell phagosomes by Toxoplasma gondii. In: Moulder, J. W. (ed.) Intracellular parasitism. CRC Press, Boca Raton, FL, p. $245-257$

Sibley, L. D., Krahenbuhl, J. L. (1988). Modification of host cell phagosomes by Toxoplasma gondii involves redistrj.bution of surface proteins and secretion of a $32 \mathrm{kDa}$ protein. Eur. J. Cell Biol. 47: 81-87

Sibley, L. D., Krahenbuhl, J. L., Adams, G. M. W., Weidner, E. (1986). Toxoplasma modifies macrophage phagosomes by secretion of a vesicular network rich in surface proteins. J. Cell Biol. 103: 867-874

Silva, S. R. L., Meirelles, S. S. L., de Souza, W. (1982). Mechanism of entry of Toxoplasma gondii into vertebrate cells. J. submicrosc. Cytol. 14: 471-482

Weidner, E., Sibley, L.D. (1985). Phagocytized intracellular microsporidian blocks phagosome acidification and phagosome-lysosome fusion. J. Protozool. 32: 311-317

Manuscript first received: September 27, 1993

Revised version accepted: August 17, 1994 